\title{
Correction to: Potato as a Source of Nutrition for Physical Performance
}

\author{
Mitch Kanter ${ }^{1,2} \cdot$ Chelsea Elkin ${ }^{1,2}$
}

Published online: 23 April 2019

(C) The Author(s) 2019

\section{Correction to: American Journal of Potato Research https://doi.org/10.1007/s12230-018-09701-8}

In the original article the affiliations for both authors were incomplete - they are correct here. Also, the conflict of interest disclaimer was missing. Both authors disclose that they are funded by Alliance for Potato Research \& Education (APRE).
Open Access This article is distributed under the terms of the Creative Commons Attribution 4.0 International License (http:// creativecommons.org/licenses/by/4.0/), which permits unrestricted use, distribution, and reproduction in any medium, provided you give appropriate credit to the original author(s) and the source, provide a link to the Creative Commons license, and indicate if changes were made.

The online version of the original article can be found at https://doi.org/ 10.1007/s12230-018-09701-8

$\triangle$ Chelsea Elkin

celkin@foodminds.com

Mitch Kanter

mkanter@foodminds.com

1 Alliance for Potato Research \& Education, PO Box 803312 ,

Chicago, IL 60680, USA

2 Food Minds, 1101 West River Parkway, Minneapolis, MN 55415, USA 